\title{
DIRETRIZES CURRICULARES DA FARMÁCIA verSUs ENADE: A ÓTICA DOCENTE
}

\author{
CURRICULAR GUIDELINES OF PHARMACY versus ENADE: \\ THE TEACHING OPTICS
}

\section{DIRECTRICES CURRICULARES FARMACIA FRENTE ENADE: LOS MAESTROS PERSPECTIVA}

\section{Joice Nedel Ott ${ }^{1}$ \\ Eva Teresinha de Oliveira Boff ${ }^{2}$ Ivan Carlos Antonello ${ }^{3}$ Mario Bernardes Wagner ${ }^{4}$ Bartira Ercília Pinheiro da Costa ${ }^{5}$}

\section{RESUMO}

O Exame Nacional de Desempenho de Estudantes (ENADE) integra o Sistema Nacional de Avaliação da Educação Superior (SINAES) como um componente curricular obrigatório nos cursos de graduação brasileiros. O objetivo deste trabalho foi analisar, em caráter crítico-reflexivo, as questões do ENADE, aplicadas aos acadêmicos de Farmácia em 2010, a fim de compreender se o perfil da prova e o intuito avaliativo são condizentes com o preconizado pelas Diretrizes Curriculares Nacionais dos cursos de Farmácia (DCNF). Através do Qualtrics Survey Software foram elaborados quatro questionários, enviados por meio digital a professores alocados a 18 cursos de Farmácia das instituições públicas e privadas do Estado do Rio Grande do Sul (RS). No total, 131 docentes avaliaram a prova do ENADE 2010. Na opinião dos professores a adequação das questões Específicas alcançou grau médio 7,78 $\pm 2,22$, sendo percebido que $63 \%$ das questões eram relacionadas à capacidade de exercício em fármacos e medicamentos, 45,5\% a habilidade crítico-reflexiva e 45,3\% atuação interdisciplinar. Já as questões de Formação Geral alcançaram nota média 5,16 22,87, auxiliando na compreensão da realidade social, cultural e econômica do meio no qual o profissional estivesse inserido 42,8\%, com caráter crítico-reflexivo 32,2\%, humanista 12,2\% e ético 10,6\%. Verificou-se que na opinião dos professores a prova de Farmácia do ENADE 2010 contempla os princípios definidos pelas DNCF, entretanto, apresenta uma distribuição assimétrica dos aspectos exigidos à formação de um profissional farmacêutico generalista.

PALAVRAS-CHAVE: Ensino superior. Currículo. Avaliação. Educação em saúde. Farmácia.

\footnotetext{
${ }^{1}$ Mestre em Ciências da Saúde pela Pontifícia Universidade Católica do Rio Grande do Sul. Farmacêutica Bioquímica. E-mail: joice.ott@acad.pucrs.br

${ }^{2}$ Doutora em Educação em Ciências. Professora do Departamento de Ciências da Vida e Pós-Graduação em Educação nas Ciências da Universidade Regional do Noroeste do Estado do Rio Grande do Sul. E-mail: evaboff@unijui.edu.br

${ }^{3}$ Doutor em Medicina pela Pontifícia Universidade Católica do Rio Grande do Sul. Professor Titular do Departamento de Medicina Interna da Pontifícia Universidade Católica do Rio Grande do Sul. Médico Nefrologista. E-mail: ivan.antonello@pucrs.br

${ }^{4}$ Doutor em Epidemiologia. Professor Associado e Adjunto da Faculdade de Medicina da Pontifícia Universidade Católica do Rio Grande do Sul. Médico, Bioestatístico. E-mail:mariobwagner@gmail.com

${ }^{5}$ Doutora em Ciências. Professora da Faculdade de Pontifícia Universidade Católica do Rio Grande do Sul.

Bióloga. E-mail: barti@pucrs.br
}

Submetido em: 08/11/2016 - Aceito em: 08/12/2016

\begin{tabular}{l|l|l|l|l|l|l} 
(C) Rev. Inter. Educ. Sup. & Campinas, SP & v.2 & n.3 & p.552-572 & set./dez. 2016 & ISSN 2446-9424
\end{tabular}




\begin{abstract}
The National Examination of Student Performance (ENADE) integrates the National System of Higher Education Assessment (SINAES) as a mandatory curriculum component in Brazilian undergraduate courses. The objective of this work was to analyze, in a critical-reflexive way, the questions of the ENADE, applied to Pharmacy academics in 2010, in order to understand if the profile of the test and the evaluative intention are consistent with the recommendations by the National Curriculum Guidelines for pharmacy courses (DCNF). Through Qualtrics Survey Software were prepared four questionnaires sent by digital means teachers allocated to 18 Pharmacy courses, public and private institutions, from the Rio Grande do Sul State (RS). A total of 131 teachers evaluatedof the ENADE 2010 test. Teachers' opinion for suitability of the Specific issues reached an average score $7.78 \pm 2.22$, most assessed exercise capacity in drugs and medicines (63\%) they demanded critical-reflective ability (45.5\%) and interdisciplinary approach (45.3\%). The General Training questions, average score was $5.16 \pm 2.87$ seconds teachers, helped in understanding the social, cultural and economic environment in which health professionals be inserted (42.8\%) and, to a lesser acuity assessed the criticalreflective character (32.2\%), humanist (12.2\%) and ethical (10.6\%). It was through the opinion of teachers, that Pharmacy ENADE 2010 test contemplates the principles defined by NDCF, however presented an asymmetric distribution of the training aspects required to the formation of the general pharmacist.
\end{abstract}

KEYWORDS: Higher education. Curriculum. Evaluation. Health education. Pharmacy.

\title{
RESUMEN
}

El Examen Nacional de Desempeño de Estudiantes (ENADE) integra el Sistema Nacional de Evaluación de la Educación Superior (SINAES) como un componente curricular obligatorio en los cursos de grado en Brasil. El objetivo de este estudio ha sido analizar con carácter crítico-reflexivo las cuestiones del ENADE aplicado a estudiantes de farmacia en 2010, con el fin de conocer el perfil de la prueba y si el intuituo evaluativo condice con las recomendaciones de las Diretrizes Curriculares Nacionales de los Cursos de Farmacia (DCNF). A través del software Resumen Qualtrics se han prepararado cuatro cuestionarios enviados por medio digital a maestros asignados a los cursos de farmacia, 18 instituciones públicas y privadas de Rio Grande do Sul (RS). Un total de 131 maestros llevó a cabo el análisis de ENADE 2010. Em la opinión de los professores, la adecuación de las cuestiones Específicas alcanzó grado mediano 7,78 $\pm 2,22$, siendo percibido que el 63\% de las cuestiones estaban relacionadas con la capacidad de ejercicio en fármacos y medicinas, el 45,5\% la habilidad crítico-reflexiva y el 45,3\% actuación interdisciplinaria. Ya las cuestiones de Formación General han alcanzado calificación promedio 5,16 $\pm 2,87$, auxiliando en la comprensión de la realidad social, cultural y económica del medio en el que estuviese inserido el profissional, el 42,8\%, con carácter crítico-reflexivo el 32,2\%, humanista el 12,2\% y ético el 10,6\%. Se ha verificado que en la opinión de los professores, el a examen de Farmacia del ENADE 2010 contempla los principios definidos por las DNCF, sin embargo, presenta una distribución asimétrica de los aspectos exigidos a la formación de un profesional farmacéutico generalista.

PALABRAS CLAVE: Educación superior. Plan de estudios. Evaluación. Educación para la salud. Farmacia.

\section{Introdução}

As Diretrizes Curriculares dos cursos de graduação proporcionaram novos rumos à educação brasileira. Enquanto orientações a serem seguidas pelas Instituições de Ensino Superior (IES) buscam assegurar a flexibilidade, a diversidade e a qualidade da formação oferecida aos estudantes, estimulam a superação das tradicionais concepções das grades curriculares, muitas vezes, meros instrumentos de transmissão de conhecimento. Neste sentido, um novo perfil de profissional passou a ser exigido, sobretudo na área da saúde: mais crítico, humanista, reflexivo e ético, a fim de contemplar uma formação vinculada ao meio social no qual o profissional será inserido (BRASIL, 2001). 
A partir das Diretrizes Curriculares Nacionais do curso de Farmácia (DCNF), o farmacêutico passa a construir o conhecimento de maneira mais ampla. Instituídas pela Resolução 2/2002, do Conselho Nacional da Educação (CNE) e da Câmara da Educação Superior (CES), as DCNF definiram princípios, fundamentos, condições e procedimentos da formação profissional, com aplicação em âmbito nacional, na organização, desenvolvimento e avaliação dos projetos pedagógicos dos cursos de Farmácia do país (BRASIL, 2002).

Transcorrida uma década de aprovação das Diretrizes, a avaliação é a principal ferramenta de organização e implementação das reformas educacionais (DIAS SOBRINHO, 2010). No Brasil, o Sistema Nacional de Avaliação da Educação Superior (SINAES) surgiu com o objetivo de assegurar o processo nacional de avaliação das instituições, dos cursos de graduação e do desempenho acadêmico de seus estudantes. Considerado um instrumento em construção, o SINAES, instituído formalmente pela Lei $\mathrm{n}^{\circ}$ 10.861/2004, tem como finalidade a melhoria da qualidade da educação superior, bem como a orientação da expansão da sua oferta, o aumento permanente da eficácia institucional, efetividade acadêmica e social e, especialmente, a promoção do aprofundamento dos compromissos e responsabilidades sociais das IES (BRASIL, 2004).

O Exame Nacional de Desempenho de Estudantes (ENADE) é um dos pilares que completa a proposta dos SINAES. Tem por objetivo avaliar o rendimento dos alunos, tanto em relação aos conteúdos programáticos previstos nas Diretrizes, quanto às habilidades e competências que os estudantes são capazes de demonstrar sobre temas, inclusive, exteriores ao âmbito específico de sua profissão, ligados à realidade brasileira, mundial e a outras áreas do conhecimento (BRASIL, 2004).

Neste contexto, a prova do ENADE apresenta questões de natureza objetiva e discursiva e, divide-se em duas partes: Formação Geral e Específica (BRASIL, 2016a). As questões de Formação Geral são comuns às diferentes áreas, destinadas a todos os cursos que participam do ENADE, com o objetivo de investigar aptidões e capacidades que os estudantes já tenham desenvolvido na sua trajetória, de forma a facilitar a compreensão de temas exteriores ao âmbito específico de sua profissão, a nível nacional e mundial. As questões do componente Específico contemplam as peculiaridades de cada curso, tanto no domínio dos conhecimentos quanto nas habilidades esperadas para o perfil profissional e investiga conteúdos do curso por meio da exploração de níveis diversificados de habilidades e saberes em cada questão (POLIDORI et al., 2006; POLIDORI, 2009).

O ENADE, enquanto componente curricular obrigatório, é realizado trienalmente (BRASIL, 2004), tornando-se um importante espaço de avaliação em larga escala. Como tal, deve ser considerado um dos componentes do sistema de avaliação nacional e não tomado isoladamente (DIAS SOBRINHO, 2010; SOUSA; FERNANDES, 2015). Aliado aos processos de avaliação de curso e instituição, o exame tende a constituir-se um importante instrumento de avaliação e de promoção da qualidade para as políticas de educação superior do país (BRASIL, 2016b; CANAN; ELOY, 2016).

\begin{tabular}{l|l|l|l|l|l|l} 
(C) Rev. Inter. Educ. Sup. & Campinas, SP & v.2 & n.3 & p.552-572 & set./dez. 2016 & ISSN 2446-9424 \\
\hline
\end{tabular}


Desde a sua criação, em 2004, o ENADE avaliou graduandos de Farmácia em cinco edições. O perfil do profissional farmacêutico definido pelas DCNF compreende uma formação generalista, humanista, crítica e reflexiva, capacitada para atuar em todos os níveis de atenção à saúde, com base no rigor científico e intelectual. Ao farmacêutico compete exercer atividades referentes aos fármacos e aos medicamentos, às análises clínicas e toxicológicas e ao controle, produção e análise de alimentos. Continuamente pautado em princípios éticos, visa à compreensão da realidade social, cultural e econômica do seu meio, dirigindo sua atuação para a transformação da realidade em benefício da sociedade. Dentre as competências e habilidades específicas do farmacêutico avaliadas no ENADE, destaca-se a atuação multiprofissional, interdisciplinar e transdisciplinar com extrema produtividade na promoção da saúde baseado na convicção científica, de cidadania e ética (BRASIL, 2002).

Rememorando a estrutura da avaliação, surgem alguns questionamentos: a prova do ENADE avalia o profissional a ser formado conforme o exigido pelas Diretrizes Curriculares? As questões são adequadas à avaliação do graduando em Farmácia? Como os professores, principais atores do processo de formação acadêmica, avaliam o instrumento ENADE?

O objetivo deste trabalho foi analisar, em caráter crítico-reflexivo, as questões do ENADE, realizado pelos acadêmicos de Farmácia no ano de 2010, a fim de compreender se, na opinião dos professores vinculados a instituições públicas e privadas do Estado do Rio Grande do Sul (RS), o perfil da prova e o intuito avaliativo são condizentes com o preconizado pelas DCNF, de modo a contribuir com uma avaliação e formação qualificada do profissional generalista.

\section{Metodologia}

Estudo transversal, exploratório, descritivo, de caráter quali-quantitativo. O presente artigo faz uma análise das respostas dos professores alocados a diferentes cursos de Farmácia do RS, participantes do estudo intitulado "Diretrizes Curriculares Nacionais do curso de graduação em Farmácia e o Sistema de Avaliação da Educação Superior: análise críticoreflexiva da prova do ENADE 2010”, aprovado pelo Comitê de Ética em Pesquisa da PUCRS através do Parecer Consubstanciado n 149.133/2012.

Foram elaborados quatro questionários diferentes (Q1, Q2, Q3 e Q4), por meio do Qualtrics Survey Software ${ }^{6}$, um serviço de organização e coleta de dados para pesquisa disponibilizado na rede. A primeira fase, comum aos quatro questionários, destinou-se a caracterizar a população de pesquisa. Dentre as informações solicitadas como idade, gênero,

\footnotetext{
${ }^{6}$ Qualtrics Survey Software: Plataforma on-line que permite criar e responder questionários. Aos pesquisadores o sistema oferece ferramentas de construção, distribuição e gestão de questionários. Aos participantes de pesquisa, o serviço garante sigilo, comodidade e segurança.

\begin{tabular}{l|l|l|l|l|l|l} 
(C) Rev. Inter. Educ. Sup. & Campinas, SP & v.2 & n.3 & p.552-572 & set./dez. 2016 & ISSN 2446-9424 \\
\hline
\end{tabular}
}


curso de formação e a mais alta qualificação, os professores puderam informar se possuíam alguma formação complementar em docência, descrevendo-a, além de, opcionalmente, indicar a(s) IES em que exerciam atividades docentes.

$\mathrm{Na}$ segunda fase, cada um dos questionários continha 10 questões distintas, originalmente transcritas do ENADE do curso de Farmácia realizado em $2010^{7}$, a serem analisadas pelos professores. As questões do ENADE foram incluídas, alternadamente, em ordem crescente, de modo que os quatro questionários tivessem tanto questões de múltipla escolha e de caráter discursivo, como questões de Formação Geral e Específicas. Deste modo, a prova composta por 40 questões (10 de Formação Geral e 30 do componente Específico) foi analisada em sua totalidade na medida em que os questionários foram distribuídos, aleatoriamente, aos participantes do estudo, conforme esquema ilustrativo da Figura 1.

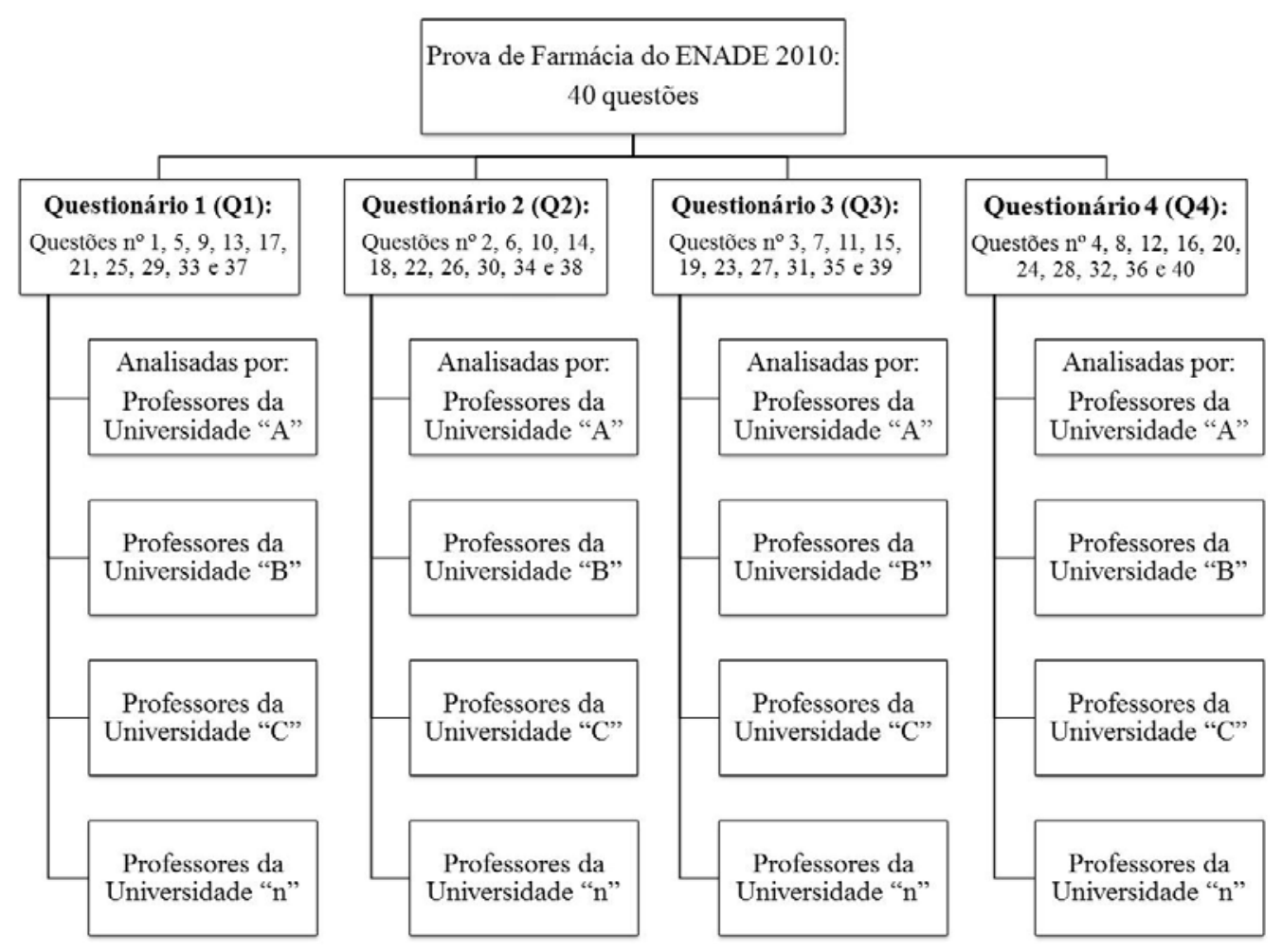

Figura 1 - Desenho metodológico aplicado ao estudo mostrando o arranjo de questões do ENADE que constituíram os questionários Q1, Q2, Q3, Q4.

Fonte: Os autores

\footnotetext{
${ }^{7}$ A prova de Farmácia do ENADE 2010 foi critério de seleção para os pesquisadores. Foram excluídas as provas de Farmácia do ENADE 2004 e 2007, pois entre os alunos ingressantes e/ou concluintes que realizaram estas provas, nestes anos, poderiam estar alunos do currículo anterior à implantação das novas DCNF. Assim, acredita-se que o melhor critério de avaliação do objetivo proposto seja o ENADE 2010, que obrigatoriamente foi realizado por alunos cujas habilidades e competências encontram-se vinculadas as DCNF, já estabelecidas nas IES.
} 
As alternativas para análise foram estabelecidas a partir de uma rigorosa apreciação das DCNF. Através de uma categorização analítica qualitativa deste documento emergiram preposições, transformadas em respostas, de única e/ou múltipla escolha, que os professores participantes da pesquisa deveriam marcar ao analisar cada questão do ENADE, a fim de relacioná-la as características de formação do profissional farmacêutico exigidas pelas DCNF.

Para melhor compreensão, a metodologia utilizada para a estruturação dos questionários é apresentada em detalhes. Cada questão da prova do ENADE foi analisada mediante três interrogativas. A primeira, de múltipla escolha, solicitava uma avaliação em relação ao perfil do profissional farmacêutico generalista, conforme estabelecido pelas DCNF (BRASIL, 2002, Art. $3^{\circ}$ ). Ou seja, buscou saber, na opinião dos professores, se as questões do ENADE 2010 avaliavam: o caráter "humanista” da formação; o caráter “crítico-reflexivo"; os "princípios éticos” exigidos; auxiliavam a "compreensão da realidade social, cultural e econômica do seu meio” ou nenhuma das respostas anteriores (NRA). Ressalta-se que, os professores poderiam marcar mais de uma alternativa válida como resposta à interrogativa, no entanto, quando a escolha NRA fosse assinalada, desmarcavam-se, automaticamente, as demais.

A segunda interrogativa relacionou as áreas de atuação do profissional farmacêutico (BRASIL, 2002, Art. $3^{\circ}$ ). Verificou-se, através da opinião dos professores, se a questão do ENADE avaliava a capacidade de exercício referente "aos fármacos e aos medicamentos”; “às análises clínicas e toxicológicas”; ao "controle, produção e análise de alimentos” ou NRA, cujas alternativas tinham caráter de escolha única.

Baseado no Artigo 50 ${ }^{\circ}$ item III, das DCNF (BRASIL, 2002), foi estabelecida a terceira interrogativa, igualmente de única escolha. Nesta, questionou-se as questões do ENADE quanto à atuação "multiprofissional”; “interdisciplinar”; "transdisciplinar” ou NRA, cujas alternativas válidas são descritas com competências e habilidades do profissional farmacêutico. Ressalta-se que para facilitar a resposta deste item, foram apresentados, na mensagem inicial expressa na página de abertura do questionário, considerações sobre termos utilizados, cujo trecho transcreve-se (QUALTRICS, 2013, p.1):

Para conceituação, na multidisciplinaridade observa-se a justaposição das disciplinas, cada uma cooperando dentro do seu saber para estudar um determinado elemento, sem que as disciplinas envolvidas no processo sejam elas mesmas modificadas ou enriquecidas (ALMEIDA FILHO, 1997). A interdisciplinaridade, ao estabelecer interação entre duas ou mais disciplinas, resulta em intercomunicação, enriquecimento recíproco e, consequentemente, em uma transformação de suas metodologias de pesquisa, visto que os contextos teóricos enfrentados pelos alunos encontram-se organizados em torno de unidades mais globais, de estruturas conceituais e metodológicas compartilhadas por várias disciplinas, enriquecendo o aprendizado (SANTOMÉ, 1998). Por fim, a transdisciplinaridade é o nível de maior integração entre as disciplinas, sem fronteiras estabelecidas, culminado em um sistema global, de níveis e objetivos múltiplos, tendo em vista uma finalidade comum dos sistemas (JAPIASSU, 2006). 
Além de tais interrogativas propostas, os professores puderam dar uma nota a cada questão do ENADE avaliada, ou seja, um valor numérico que expressasse a sua opinião em relação à adequação da questão à prova, sendo 10 o grau máximo. Para finalizar, comentários e considerações adicionais poderiam ser acrescentados, espontaneamente, pelos professores a cada análise, em um campo de resposta livre.

Os questionários foram enviados, por meio digital, a professores de 18 cursos de Farmácia de IES públicas e privadas do RS. Tais instituições demonstraram aceite à participação no estudo através do retorno de uma Carta de Autorização, assinada pelo coordenador. O convite foi enviado a 24 cursos de Farmácia do estado, de 21 IES diferentes. Como critério de inclusão preconizou-se IES do RS, com cursos de graduação em Farmácia autorizados pelo Ministério da Educação (BRASIL, 2012). Por conseguinte, foram convidados a contribuir com o estudo, docentes alocados aos cursos de Farmácia participantes, independente de terem formação farmacêutica.

A análise estatística dos dados empregou o programa Statistical Package for Social Science - SPSS (Chigago, IL, EUA) versão 21.0. As variáveis categóricas foram comparadas pelo Teste Qui-quadrado $\left(\chi^{2}\right)$ e os resultados apresentados em frequência absoluta e relativa. As variáveis contínuas foram expressas como média \pm desvio padrão (DP) e analisadas por ANOVA. A regressão linear foi aplicada para verificar possível correlação entre variáveis. Todos os testes foram aplicados utilizando-se intervalo de confiança (IC) de 95\%, considerando-se p<0,05 como nível mínimo de significância estatística.

\section{Resultados}

Participaram do estudo 18 cursos de Farmácia do RS (de 16 IES diferentes), 04 públicos e 14 privados, contendo, respectivamente, 175 e 375 professores alocados à graduação supracitada. Durante o período do estudo os questionários foram acessados, no sistema Qualtrics, por 237 professores. Responderam, por completo, a primeira fase dos questionários 75,9\% ( $\mathrm{n}=180)$ e destes, avançaram para a segunda fase 72,8\% ( $\mathrm{n}=131)$ dos professores. Ao final, a distribuição docente por questionário foi: Q1: 31,3\% (41/131); Q2 e Q4: 23,7\% (31/131) e Q3: 21,3\% (28/131).

A Tabela 1 caracteriza os professores participantes da pesquisa quanto à idade, gênero, curso de graduação, formação complementar, bem como a IES pertencente. A análise estatística não detectou diferença entre os grupos de respondedores dos diferentes questionários com relação às características da amostra. Observa-se, nos quatro questionários, a participação prevalente de professores farmacêuticos (67\%), do sexo feminino (71\%), com qualificação stricto sensu (mestrado/doutorado - 95\%) e vinculados a IES privada (66\%). Entre os professores que responderam por completo a pesquisa, a idade mínima descrita foi 26 anos e a máxima 69 anos.

\begin{tabular}{l|l|l|l|l|l|l} 
(C) Rev. Inter. Educ. Sup. & Campinas, SP & v.2 & n.3 & p.552-572 & set./dez. 2016 & ISSN 2446-9424 \\
\hline
\end{tabular}


Tabela 1 - Caracterização da amostra de pesquisa em relação aos questionários aplicados

Não
respondentes

\section{Questionário}

\begin{tabular}{|c|c|c|c|c|c|c|c|}
\hline \multirow[b]{2}{*}{ Variáveis } & \multirow[b]{2}{*}{$\mathrm{n}=106$} & \multirow[b]{2}{*}{$\mathrm{n}=131$} & & & & & \multirow[b]{2}{*}{$\mathbf{p}$} \\
\hline & & & $\begin{array}{c}\mathbf{1} \\
\mathrm{n}=41\end{array}$ & $\begin{array}{c}2 \\
\mathrm{n}=31\end{array}$ & $\begin{array}{c}3 \\
n=28\end{array}$ & $\begin{array}{c}\mathbf{4} \\
\mathrm{n}=31\end{array}$ & \\
\hline \multirow{2}{*}{$\begin{array}{c}\text { Idade: (anos) } \\
\text { média } \pm D P\end{array}$} & $\mathrm{n}=51$ & $\mathrm{n}=125$ & $\mathrm{n}=39$ & $\mathrm{n}=31$ & $\mathrm{n}=25$ & $\mathrm{n}=30$ & \multirow{2}{*}{$0,72^{\#}$} \\
\hline & $42 \pm 10$ & $42 \pm 10$ & $41 \pm 10$ & $42 \pm 10$ & $43 \pm 10$ & $42 \pm 9$ & \\
\hline \multirow{2}{*}{$\begin{array}{c}\text { Feminino } \\
\mathrm{n}(\%)\end{array}$} & $\mathrm{n}=51$ & $\mathrm{n}=127$ & $\mathrm{n}=39$ & $\mathrm{n}=31$ & $\mathrm{n}=26$ & $\mathrm{n}=31$ & \multirow{2}{*}{$0,097^{\S}$} \\
\hline & $34(67)$ & $90(71)$ & $32(82)$ & $21(68)$ & $14(54)$ & $23(74)$ & \\
\hline \multirow{2}{*}{$\begin{array}{c}\text { Farmacêutico } \\
\text { n(\%) }\end{array}$} & $\mathrm{n}=50$ & $\mathrm{n}=121$ & $\mathrm{n}=38$ & $\mathrm{n}=30$ & $\mathrm{n}=23$ & $\mathrm{n}=30$ & \multirow{2}{*}{$0,81^{\S}$} \\
\hline & $35(70)$ & 81(67) & $27(71)$ & $19(63)$ & $14(61)$ & $21(70)$ & \\
\hline \multirow{2}{*}{$\begin{array}{l}\text { Qualificação: } \\
\text { M/D - n(\%) }\end{array}$} & $\mathrm{n}=51$ & $\mathrm{n}=128$ & $\mathrm{n}=39$ & $n=31$ & $\mathrm{n}=27$ & $\mathrm{n}=31$ & \multirow{2}{*}{$0,22^{\S}$} \\
\hline & $51(100)$ & 122(95) & $35(90)$ & $31(100)$ & $26(96)$ & 30(97) & \\
\hline \multirow{2}{*}{$\begin{array}{c}\text { FC: Possui } \\
\text { n(\%) }\end{array}$} & $\mathrm{n}=49$ & $\mathrm{n}=131$ & $\mathrm{n}=41$ & $\mathrm{n}=31$ & $\mathrm{n}=28$ & $\mathrm{n}=31$ & \multirow{2}{*}{$0,74^{\S}$} \\
\hline & $14(29)$ & $45(34)$ & $14(34)$ & $13(42)$ & $9(32)$ & $9(29)$ & \\
\hline \multirow{2}{*}{$\begin{array}{l}\text { IES: Privada } \\
\text { n(\%) }\end{array}$} & $\mathrm{n}=37$ & $\mathrm{n}=128$ & $\mathrm{n}=41$ & $n=29$ & $\mathrm{n}=28$ & $\mathrm{n}=30$ & \multirow{2}{*}{$0,89^{\S}$} \\
\hline & $28(76)$ & $85(66)$ & $29(71)$ & $18(62)$ & $18(64)$ & $20(67)$ & \\
\hline
\end{tabular}

Não respondentes: Professores que não responderam por completo os questionários; Respondentes: Professores que completaram a análise dos questionários; n: número de professores, DP: Desvio Padrão; F: Feminino; n: frequência absoluta; \%: frequência relativa; M/D: mestrado/doutorado; FC: Formação Complementar; IES: Instituição de Ensino Superior; p: significância estatística p<0,05; \#Anova; §Qui-quadrado $\left(\chi^{2}\right)$.

Fonte: Os autores

Conforme o questionário avançava alguns professores deixaram de expressar a sua opinião, ou seja, ao longo do questionário diminuíram, continuamente, o número de questões respondidas. Para testar a consistência de análise dos dados do presente estudo e verificar possível influência da perda de respondentes ao longo dos questionários, aplicou-se o teste de regressão linear.

Neste caso, não foi evidenciada uma correlação estatisticamente significativa entre as notas atribuídas às questões de Formação Geral e o número de professores respondedores $(\mathrm{r}=0,15 ; \mathrm{p}=0,69)$, da mesma forma entre as questões do componente Específico e o número de respondedores $(r=0,21 ; p=0,26)$. Os dados encontram-se plotados no gráfico da Figura 2, cuja linha de tendência mostra a queda no número de professores respondentes no avançar dos questionários. 
Em relação à avaliação docente para cada questão do ENADE, expressa na Figura 2 em grau, as 10 primeiras questões, oito objetivas e duas dissertativas, que compreendem o

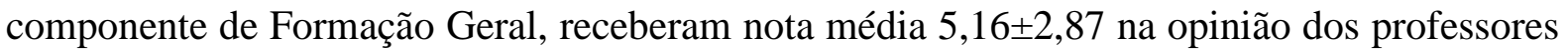
respondedores. Já às questões Específicas, 27 objetivas e três discursivas, foi designada nota média 7,78 $\pm 2,22$ quanto à adequação ao método avaliativo, segundo os participantes.

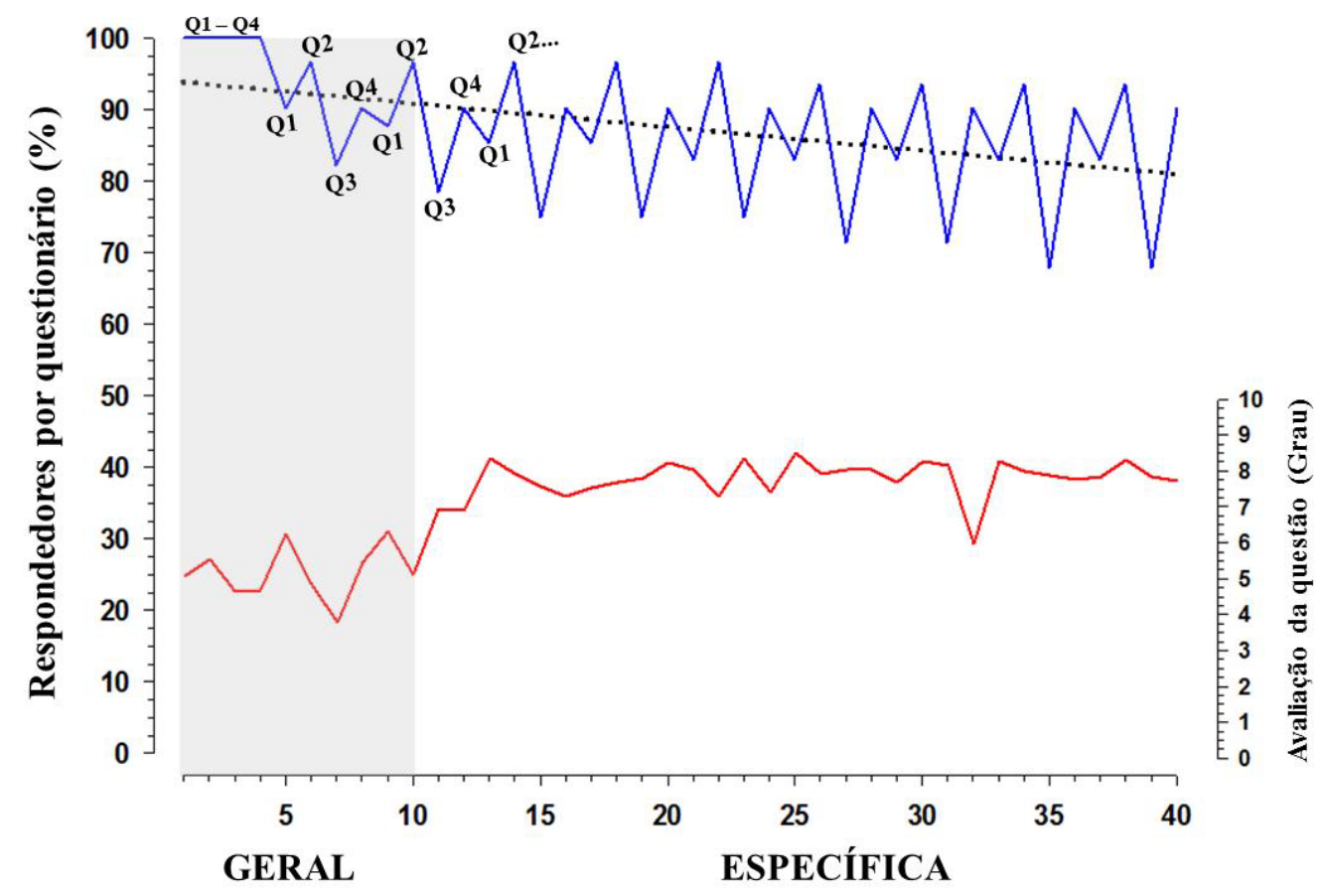

Questão do ENADE

Figura 2 - Análise das questões do ENADE 2010, do Curso de Farmácia, em relação ao número de professores respondedores e a nota designada a cada questão.

Fonte: Os autores

Após garantir a consistência dos resultados, mantida independentemente do número de respondedores, prosseguiu-se com a apreciação das questões do ENADE, avaliadas pelo corpo docente em relação aos critérios determinados pelas DCNF. Cabe destacar que, independente da questão ter caráter Geral ou Específico às alternativas de análise eram idênticas, justamente para observar coerência na interpretação docente. Dessa forma, todas as questões foram analisadas quanto ao perfil estabelecido ao profissional generalista, à área de atuação e ao exercício profissional, enquanto competências e habilidades específicas do farmacêutico, exigidas pelas DCNF.

Análise das questões do ENADE 2010 em relação ao perfil profissional do farmacêutico generalista 
A Figura 3 expressa, em porcentagem, a média das respostas dos professores para as questões Gerais e Específicas, analisadas em relação ao perfil profissional do farmacêutico generalista (BRASIL, 2002, Art. $3^{\circ}$ ). Ressalta-se que neste critério de investigação, mais de uma alternativa poderia ser assinalada pelo docente, a fim de caracterizar o perfil avaliativo de cada questão do ENADE.

Na opinião dos professores, as questões de Formação Geral do ENADE 2010 auxiliaram o aluno, em maior acuidade, na compreensão da realidade social, cultural e econômica do meio ao qual estivesse inserido, habilidade designada, em média, por 42,8\% dos respondedores. No componente específico, em média, 45,5\% dos professores indicaram o predomínio da capacidade crítica-reflexiva para a resolução das questões.

Observa-se que aproximadamente $10 \%$ dos professores consideraram que as questões, tanto gerais quanto específicas, apresentavam enfoque ético e humanista.

A análise estatística $\left(\chi^{2}\right)$ evidenciou que a distribuição das respostas nas categorias analisadas: "humanista”, "crítico-reflexivo" e "compreensão da realidade social, cultural e econômica do meio", não é a mesma entre os dois lotes de questões: Gerais e Específicas $(\mathrm{p}<0,001)$. Contudo, a categoria que abordava os princípios “éticos” exigidos, não apresentou significância estatística ( $\mathrm{p}=0,245)$ entre os grupos de questões, demonstrado na Figura 3.

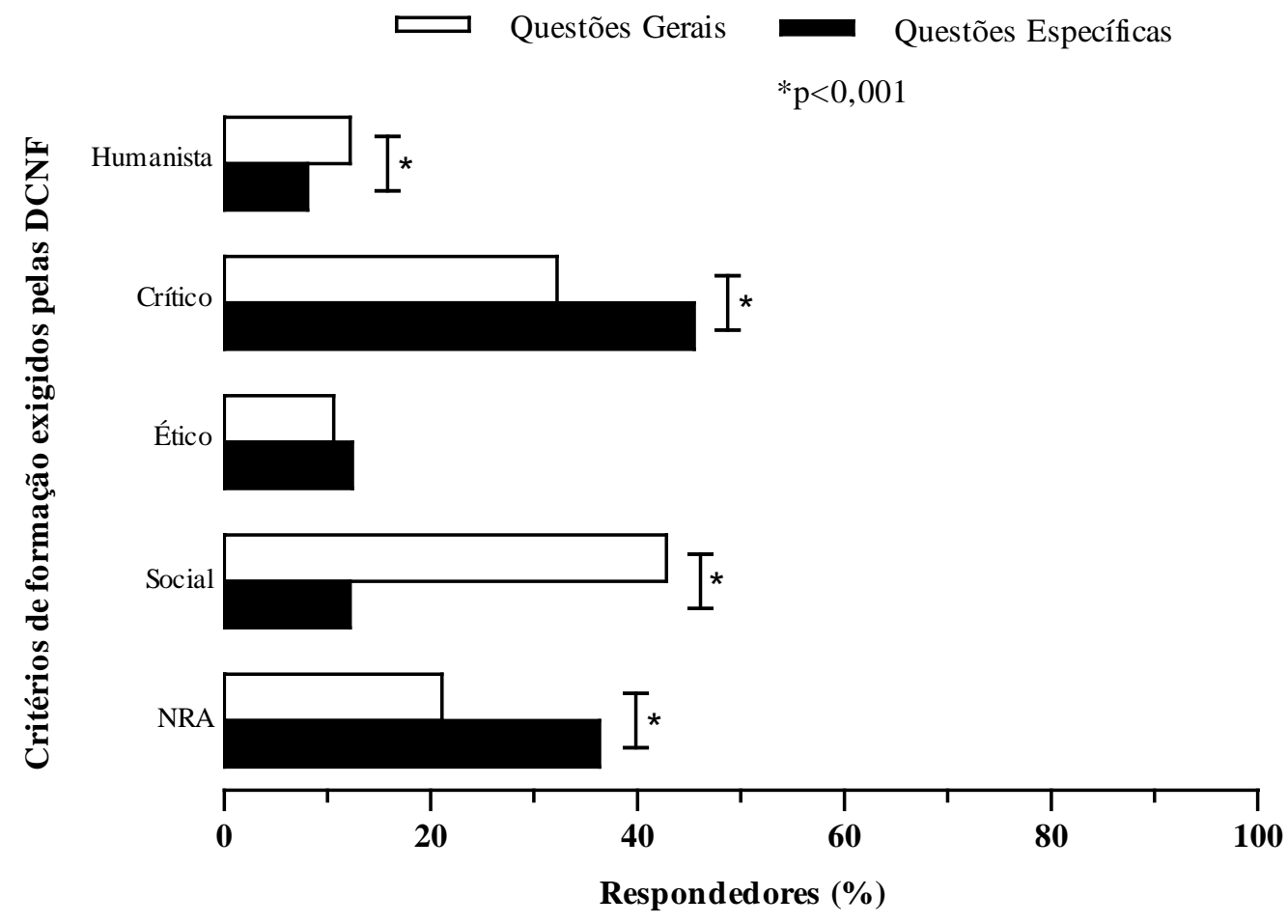

Figura 3 - Análise das questões do ENADE 2010 do curso de Farmácia, segundo critérios exigidos pelas DCNF à formação generalista.

Fonte: Os autores 
Análise das questões do ENADE 2010 em relação ao exercício profissional

As grandes áreas de atuação do farmacêutico, expressas nas DCNF (BRASIL, 2002, Art. $3^{\circ}$ ) e avaliadas nas questões do ENADE 2010, estão representadas na Figura 4, segundo a opinião dos professores respondedores.

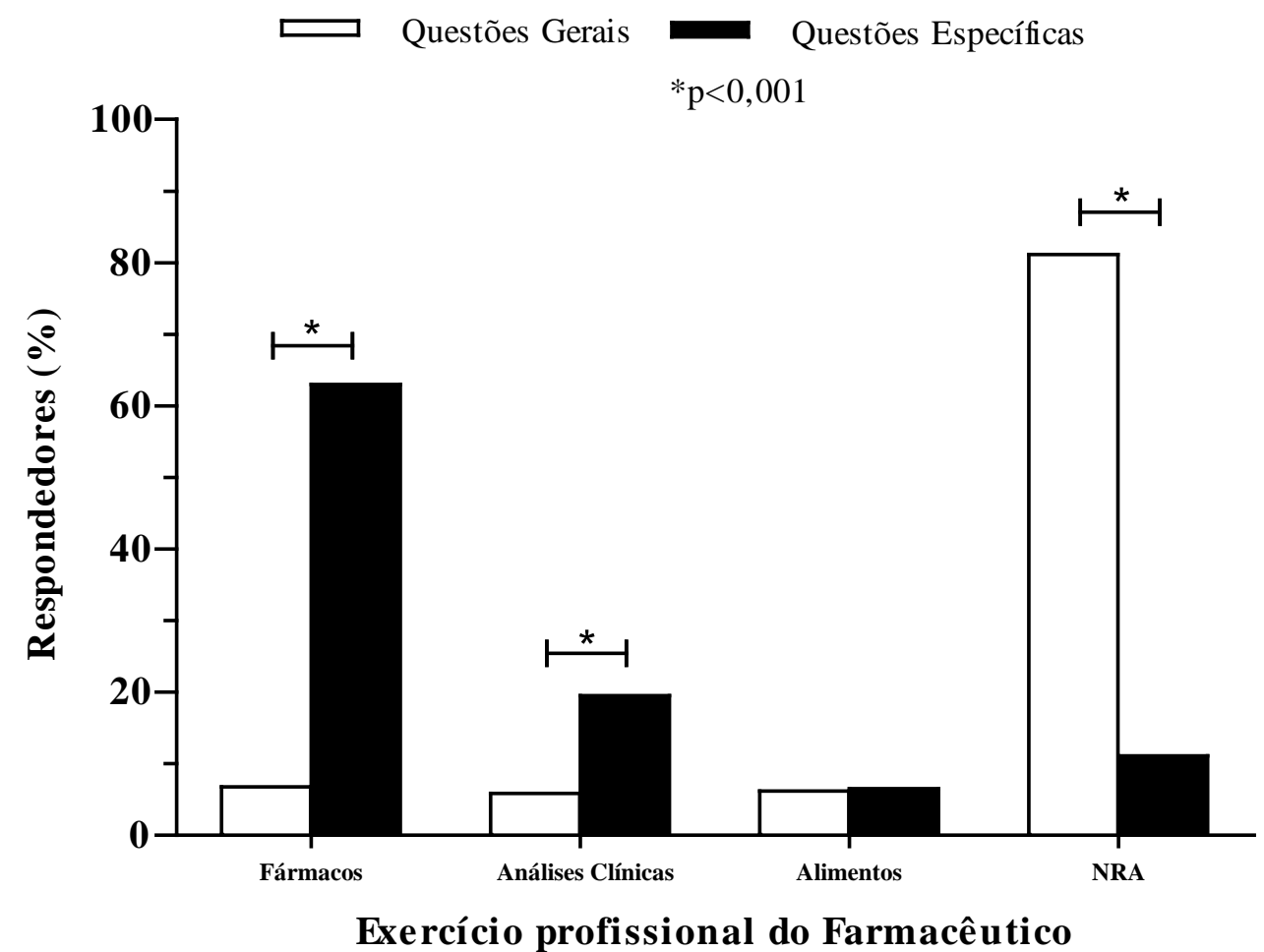

Figura 4 - Análise das questões do ENADE 2010 do curso de Farmácia, em relação ao exercício profissional do farmacêutico generalista, de acordo com as DCNF.

Fonte: Os autores

Através do $\chi^{2}$ evidenciou-se distribuição assimétrica das respostas nas categorias de análise propostas, entre as questões Gerais e Específicas ( $\mathrm{p}<0,001)$, com exceção da área de atuação em “controle, produção e análise de alimentos” ( $p=0,935)$, que não apresentou diferença estatística entre os dois grupos de questões.

Em média, a maioria dos professores $(81,1 \%)$ não associou as áreas de atuação características do profissional farmacêutico às questões de Formação Geral. A análise docente indicou a capacidade de exercício em "fármacos e medicamentos" como a forma de atuação predominante avaliada nas questões do componente Específico, habilidade expressa por $63 \%$ dos professores respondedores, seguida do exercício profissional em análises clínicas (19,5\%) e análise de alimentos (6,5\%). 
Análise das questões do ENADE 2010 em relação à atuação profissional

A interrogativa proposta neste caso foi a verificação de cada questão do ENADE quanto à capacidade de atuação multiprofissional, interdisciplinar e transdisciplinar, competências e habilidades específicas do farmacêutico (BRASIL, 2002, Art. 5º).

Estatisticamente $\left(\chi^{2}\right)$ identificou-se desequilíbrio nas respostas docentes para as categorias de análise entre as questões Gerais e Específicas $(\mathrm{p}<0,01)$. Exceto à atuação “multiprofissional” ( $p=0,169)$, sem diferença entre os grupos, demonstrado na Figura 5.

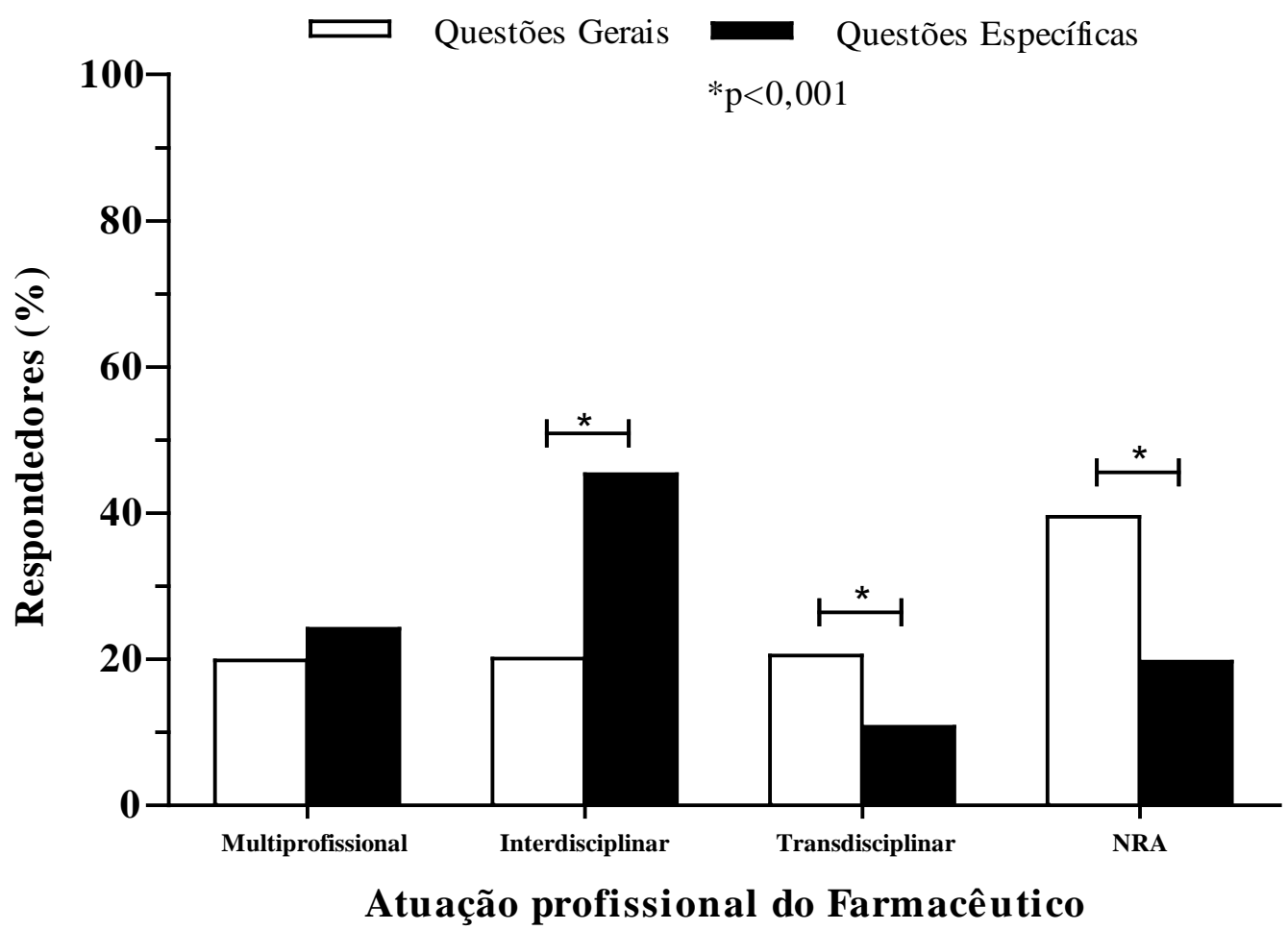

Figura 5 - Análise das questões do ENADE 2010 do curso de Farmácia, em relação à atuação profissional do farmacêutico generalista, de acordo com as DCNF.

Fonte: Os autores

Através das respostas docentes percebe-se que a prática interdisciplinar é predominante entre as questões Específicas, citada em média por 45,3\% dos respondedores, sucedida pela aptidão multiprofissional (24,2\%) e transdisciplinar (10,8\%). Mas, para alguns professores estes aspectos não foram avaliados pelas questões da Prova do ENADE 2010. Nos itens de Formação Geral, 39,5\% dos respondedores não identificaram avaliação do aluno quanto à capacidade de atuação multiprofissional, inter ou transdisciplinar, expressos através da alternativa NRA. 


\section{Discussão}

A investigação foi realizada no sentido de verificar a aplicabilidade das definições das DCNF nas questões avaliativas do desempenho de alunos graduandos em Farmácia. Não somente pelo fato das propostas estabelecidas nas DCNF ocasionarem discussões e mudanças significativas, que envolveram, entre outros aspectos, o componente humanístico e crítico da profissão (FURTADO, 2008). Mas, em grande parte, devido a pouca clareza das Diretrizes em relação ao significado da formação generalista e, principalmente, como tais profissionais estariam sendo avaliados e inseridos no mercado de trabalho (CECY, 2011; BOFF, 2012).

Por esta razão, a análise crítico-reflexiva do instrumento ENADE realizada neste estudo deu-se através da interpretação dos pressupostos das DCNF, os quais foram investigados em meio às questões do exame, a fim de verificar a coerência da metodologia de avaliação frente à formação de profissionais generalistas. Buscou-se, para isso, a percepção do corpo docente, inserido de maneira contínua no universo da pesquisa, vivenciando diariamente as adaptações às DCNF, enquanto facilitadores e mediadores do processo ensinoaprendizagem. Tal observação não só justifica os caminhos metodológicos adotados como também dá início as discussões relacionadas aos resultados obtidos no estudo proposto.

A consistência dos dados foi sustentada independente da utilização de quatro questionários de pesquisa, o que tornou viável a apreciação das 40 questões do ENADE, autônoma, inclusive, da redução no número de professores respondedores. A homogeneidade dos respondentes entre os questionários propostos, predominantemente farmacêuticos e com especialização stricto sensu (mestrado/doutorado) evidenciada na Tabela 1, permitiu que a análise das respostas fosse unificada e aprofundada, na tentativa de elucidar as inquietudes apresentadas incialmente pelo estudo.

Embora o número de questões respondidas tenha diminuído (Figura 2), muito provavelmente pelo cansaço proporcionado pela extensão dos questionários, não houve prejuízo quanto à interpretação dada pelos docentes à percepção de adequação das questões no ENADE. Duas são as situações que contextualizam a afirmação. A primeira é representada pelo grau atribuído pelos professores a cada questão, das gerais às específicas, que em média tendeu a aumentar, confirmando a coesão das respostas entre os participantes e a acuidade empregada em cada análise.

A segunda observação parte do princípio que, independente da questão do ENADE ter caráter Geral ou Específico às alternativas de análise eram idênticas. Dessa forma, mesmo evidenciada uma distribuição assimétrica em relação ao exercício profissional do farmacêutico (Figura 4) na opinião dos professores, às questões referentes à Formação Geral não traduziram os aspectos neste item avaliados, quando mais de $80 \%$ dos docentes não associaram áreas específicas de atuação do farmacêutico às questões de conhecimento geral. Fato que traduz coerência quanto aos objetivos propostos, já que a resolução de questões do componente Geral não necessita de competências exclusivas do farmacêutico. Pelo contrário,

\begin{tabular}{l|l|l|l|l|l|l} 
(c) Rev. Inter. Educ. Sup. & Campinas, SP & v.2 & n.3 & p.552-572 & set./dez. 2016 & ISSN 2446-9424 \\
\hline
\end{tabular}


as questões gerais são respondidas por todos os alunos dos diferentes cursos participantes do ENADE a cada edição.

Verificou-se, em meio às respostas dos professores, que as características que compõe o perfil generalista são avaliadas de forma díspar entre as questões da prova do ENADE, com predomínio de habilidades e competências que podem não dar o significado pretendido para a avaliação. O fato recebe destaque, quando, na avaliação do exercício profissional farmacêutico (Figura 4) observa-se um predomínio de questões da área de atuação referente a fármacos e a medicamentos, opção apontada por mais de 60\% dos professores, muito aquém dos 6,5\% de indicações a questões referentes à análise de alimentos, área de atuação que o profissional deve estar, igualmente, apto a desempenhar.

Do mesmo modo, observou-se um desequilíbrio entre as características de formação exigidas (Figura 3) e a capacidade de atuação profissional (Figura 5), tanto nas questões Gerais quanto Específicas. Conforme os professores respondentes houve predomínio de questões que possibilitaram a compreensão da realidade social, cultural e econômica na Formação Geral. Entre as Específicas, a preponderância foi de questões crítico-reflexivas, com caráter interdisciplinar.

Diante dos preceitos que envolvem as DCNF, esperava-se que as questões Gerais tivessem características humanistas e éticas em maior proporção que o apontado pelos docentes. As Diretrizes, enquanto orientações a serem seguidas pelas IES deram novos rumos à educação brasileira, na qual a formação do profissional deve contemplar o sistema de saúde vigente no país (CECCIM; FEUERWERKER, 2004). Ou seja, é exatamente o caráter humanista, ético e social da formação que contextualiza o lado compassivo do profissional com o paciente, sensibilidade esperada nos agentes atuantes na área da saúde.

Entretanto, isso não significa que o profissional formado não seja humanista e/ou ético. Tal observação indica que o ENADE, na opinião dos professores respondedores do questionário proposto, não está avaliando estas caraterísticas. Ou melhor, as DCNF apontam aspectos importantes da formação profissional que o ENADE está avaliando sem atender ao equilíbrio proposto.

Acredita-se que a intenção avaliativa do exame frente ao perfil de formação generalista exigido pelas Diretrizes não é, suficientemente, clara. Isso porque, mais de $20 \%$ dos professores na análise do componente de Formação Geral e, mais de 35\% diante das questões Específicas, indicaram que nenhuma das características correspondentes ao perfil generalista em formação estaria sendo avaliada. As questões não se relacionavam com o caráter humanista, com a capacidade crítica e reflexiva ou com os princípios éticos exigidos, nem tampouco auxiliam a compreensão da realidade social, cultural e econômica dos profissionais. 
Seriam, neste caso, as respostas fruto da falta de perceptibilidade docente em relação aos princípios de formação e avaliação exigidos? Ou seria uma maneira de protestar pela não conformidade com a implementação das reformas educacionais e/ou as metodologias de avaliação utilizadas?

Faz parte do conhecimento comum que toda mudança encontra resistências, suscita dissabores e gera polêmica. Principalmente as mais radicais como a que cria a formação generalista ou institui novos métodos avaliativos, em larga escala. Para além dos propósitos descritos do exame, o ENADE, dentro do universo acadêmico, provoca muitos debates quanto a sua estruturação, conforme explanação descrita nos estudos de Francisco; Monteiro (2016), bem como entre aqueles que se opõem a sua execução nos moldes em que ele se apresenta. O fato ficou evidente na opinião dos professores respondedores da pesquisa, através da análise das questões a partir dos princípios das DCNF e por meio das notas expressas quanto à adequação das questões Gerais e Específicas na prova avaliada. Visivelmente, as questões do componente de Formação Geral receberam, em média, notas menores que as Específicas, demonstrando a insegurança dos professores frente aos conhecimentos avaliados no profissional a ser formado.

Diante do exposto percebe-se que a principal discussão se deve à aplicabilidade das questões do componente de Formação Geral no exame, questionada por uma parcela de professores participantes da pesquisa quanto à capacidade avaliativa do profissional em questão. Acredita-se que a intenção de avaliar conhecimentos gerais no desempenho do aluno é clara e legítima, pois qualquer que seja a formação superior, esta não admite profissionais alienados à realidade social, política e ambiental do país e do mundo. No entanto, entende-se que o questionamento se dá pela falta de relação do contexto apresentado com o exercício profissional, principalmente de profissionais da área da saúde, como o farmacêutico, peça chave na qualidade dos serviços prestados.

O fato de a prova do ENADE conter questões para a avaliação de conhecimentos gerais do aluno está em acordo pleno com os princípios definidos para a formação do profissional generalista. São recomendações das DCNF os conteúdos considerados essenciais para o curso de Farmácia, que devem contemplar áreas das ciências exatas, biológicas e da saúde, com conteúdos teóricos e práticos de ciências farmacêuticas, e também teores das ciências humanas e sociais (BRASIL, 2002). Todavia, conforme discussão alavancada através da opinião dos professores, os conteúdos propostos para a avaliação do acadêmico deveriam estar em associação às dimensões da relação indivíduo/sociedade, contribuindo para a compreensão de determinantes sociais, culturais, comportamentais, psicológicos, ecológicos, éticos, legais, entre outros, mas tendo como suporte à atividade farmacêutica, ou seja, relacionados ao processo saúde-doença do cidadão, da família e da comunidade, integrado a realidade epidemiológica e profissional.

Assim, acredita-se que a prova do ENADE contempla aos princípios definidos pelas DNCF quanto à formação do profissional farmacêutico generalista, entretanto, apresenta

\begin{tabular}{l|l|l|l|l|l|l} 
(C) Rev. Inter. Educ. Sup. & Campinas, SP & v.2 & n.3 & p.552-572 & set./dez. 2016 & ISSN 2446-9424
\end{tabular}


percalços. Os achados aproximam-se das discussões de Rothen, Nasciutti (2008) e Verhine; e Dantas (2005), cujos estudos demonstram que o exame apresenta limitações que possam interferir no desempenho dos estudantes de graduação ao avaliar apenas competências e habilidades cognitivas necessárias à realização de uma prova, deixando de avaliar outras, como por exemplo, as habilidades necessárias para procedimentos realizados em laboratórios, indispensáveis ao profissional farmacêutico em questão.

Como sugestão, os resultados do ENADE devem ser analisados considerando as limitações que compõem o instrumento de avaliação. Acredita-se que o exame apresente padrões que não condizem, ainda, com a realidade vivenciada no interior da maioria das IES, conforme exemplificam os resultados da pesquisa de Rodrigues e Peixoto (2009). Em entrevistas com coordenadores de cursos de graduação de uma Universidade Federal, os autores descreveram que o ENADE não apresentou na prática contribuições efetivas ao aprimoramento e ao aperfeiçoamento dos cursos de graduação avaliados (RODRIGUES; PEIXOTO, 2009).

Ressalta-se, neste momento, um dos objetivos fundamentais do ENADE: proporcionar ao curso e a IES, através do retorno sobre a avaliação realizada, muito mais que um estímulo, mas um processo de reflexão e debate sobre os resultados alcançados, instituindo melhorias caso sejam necessárias. Tal característica diagnóstica e, principalmente, o aprimoramento da qualidade do ensino é o que se almeja identificar a partir de análises e discussões como esta.

A busca pela excelência e qualidade na educação superior não é preocupação somente do sistema de ensino brasileiro, cujos estudos inclusive despontam do estado do RS (SANTANA et al., 2010), como na presente pesquisa. Recentes manuscritos internacionais reportam a mesma ansiedade a cerca da garantia da qualidade educacional (VARELAPETITO, 2011; ZOU et al., 2012; LEE et al., 2013; LU; LEMONDE, 2013). Com sistemas de avaliação peculiares, metodologias e prazos distintos, as IES buscam gerenciar a formação do aluno, futuro profissional, com ênfase nos resultados da aprendizagem e na melhoria contínua.

Na prática do sistema educacional brasileiro, o ENADE acabou se tornando um instrumento que determinou ranhuras na credibilidade do SINAES, especialmente por ser considerado o mecanismo de composição dos principais indicadores de qualidade de cursos e instituições. O exame passou a ser questionado quanto a sua validade, já que se apropriou basicamente do desempenho dos estudantes e de aspectos que não estavam previstos inicialmente na estrutura do SINAES, consolidando-se como o principal direcionador de ações das instituições e dos órgãos reguladores por meio de sua inferência na composição dos indicadores de qualidade de cursos e instituições (FRANCISCO et al., 2012).

Ao se saber que o ENADE é um dos instrumentos de avaliação e informação do SINAES, compreende-se que ele faz parte, portanto, de um sistema que busca avaliar cursos e instituições e que, para fazê-lo, utiliza-se também, mas não só, das informações geradas

\begin{tabular}{l|l|l|l|l|l|l} 
(C) Rev. Inter. Educ. Sup. & Campinas, SP & v.2 & n.3 & p.552-572 & set./dez. 2016 & ISSN 2446-9424
\end{tabular}


pelos estudantes. Assim, o que o exame mede não é a qualidade do curso, mas o desempenho dos estudantes de cada curso em relação às Diretrizes Curriculares Nacionais (RISTOFF; GIOLO, 2006).

Na opinião de Dias Sobrinho (2010) não há dúvida de que os exames em larga escala são úteis para subsidiar as ações dos operadores do estado concernentes à educação. Entretanto, é duvidoso que produzam efeitos pedagógicos significativos se não contam com a adesão de professores e alunos.

Dessa forma, sem contar a obrigatoriedade de participação do estudante como requisito ao cumprimento do componente curricular obrigatório ENADE, a diferença fundamental está no comprometimento docente e discente com o novo paradigma, seja na forma como são ministrados os conteúdos ou como o processo avaliativo é conduzido (HORTA, 2014). Ao relembrar que vivemos uma fase de transição, a avaliação como instrumento de efetivação das reformas educacionais deve estar relacionada com as transformações desejadas não somente para a educação superior, mas para a sociedade em geral, do presente e do futuro.

As expectativas na formação dos profissionais da área da saúde, entre eles o farmacêutico, incluem, para além do domínio de conteúdos, o desenvolvimento de posturas e processos que constituem o desenho de um perfil profissional generalista. Coadunadas a essas concepções, as DCNF elegeram o desenvolvimento de competências gerais e específicas, como meta orientadora na formação acadêmica sem perder o vínculo ao domínio de conhecimentos, saberes e práticas próprias da área profissional. Por conseguinte, à opção avaliativa do SINAES sobre o desempenho estudantil, mais precisamente à prova do ENADE, cabe refletir essa tendência, ao priorizar o desenvolvimento de competências entre os aspectos a serem avaliados, tendo como foco o processo no qual elas se constituem e o contexto de aprendizagem em que se configuram.

\section{Conclusão}

A análise crítico-reflexiva das questões da prova de Farmácia do ENADE 2010, através da opinião de professores de instituições públicas e privadas do RS, revelou uma distribuição assimétrica dos aspectos de formação exigidos pelas DCNF na prova do ENADE

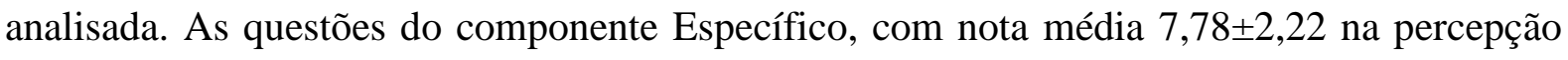
docente quanto à adequação no exame, avaliaram mais a capacidade de exercício em fármacos e medicamentos, exigiram habilidade crítico-reflexiva do estudante e atuação interdisciplinar. As questões de Formação Geral, que receberam em média nota 5,16 2,87 na opinião dos professores, auxiliaram na compreensão da realidade social, cultural e econômica do meio no qual o profissional estivesse inserido e, em menor acuidade, avaliaram o caráter crítico-reflexivo, humanista e os princípios éticos exigidos pelas DCNF. 
Embora se acredite que o atual sistema de avaliação do ensino superior possa, de fato, contribuir para a melhoria da qualidade na formação profissional, a proposta do ENADE apresenta limitações em seu processo de avaliação junto aos estudantes. Essas limitações tornaram-se evidentes na opinião dos professores, que revelaram um desequilíbrio no caráter avaliativo do ENADE 2010 frente a características essenciais apontadas pelas DCNF, a formação profissional do farmacêutico generalista.

Apesar do estudo realizado não atender à capacidade de realizar inferências e generalizações, quando os dados obtidos retratam a opinião dos professores respondedores, especificadamente sobre o ENADE 2010, acredita-se que os resultados da presente pesquisa possam contribuir para que a comunidade, interna e/ou externa à IES, conheça melhor o exame e, assim, seja capaz de avaliá-lo no contexto da política educacional nacional, que constantemente tem se voltado para a melhoria na qualidade do ensino. Na busca pelo aperfeiçoamento constante, incentivos a pesquisas como esta impulsionam a edificação de um processo avaliativo capaz de determinar a qualidade da formação dos profissionais que estão sendo inseridos na sociedade, a saber se, a partir da formação generalista oferecida, as necessidades sociais estão sendo supridas de maneira eficaz, em todos os níveis de atenção à saúde.

\section{Referências}

ALMEIDA FILHO, Naomar. Transdisciplinaridade e Saúde Coletiva. Ciência \& Saúde Coletiva. v.2, n.1-2, 1997.

BRASIL. Ministério da Educação. Conselho Nacional de Educação. Câmara de Educação Superior. Parecer CNE/CES 1.300/2001. Despacho do Ministro em 4/12/2001. Diário Oficial da União, Brasília, DF. Publicado em: 07 dez. 2001. Seção 1, p. 25.

BRASIL. Ministério da Educação. Conselho Nacional de Educação. Câmara de Educação Superior. Resolução CNE/CES 2/2002. Diário Oficial da União, Brasília, DF. Publicado em: 04 mar. 2002. Seção 1, p. 9.

BRASIL. Casa Civil. Lei no 10.861, de 14 de Abril de 2004. Diário Oficial da União, Brasília, DF. Publicado em: 15 abr. 2004. Seção 1, p. 3-4.

BRASIL. Ministério da Educação. INEP. SINAES. ENADE 2010. Prova de Farmácia. 05. nov. 2010, 24 p. Disponível em: <http://portal.inep.gov.br/provas-e-gabaritos>.

BRASIL. Ministério da Educação. IES. e-MEC. Instituições de educação superior e cursos cadastrados. 2012. Disponível em: <http://emec.mec.gov.br/>.

BRASIL. Ministério da Educação. Portaria Normativa n. 5, de 09 de março de 2016. Diário Oficial da União. Brasília, DF. Publicado em: 10 de março 2016, Seção 1, n. 47. 2016a.

BRASIL. Ministério da Educação. INEP. Diretoria de Avaliação da Educação Superior. DAES. Manual do ENADE 2016. Brasília, DF. 25 de maio de 2016. 118p. Disponível em:

\begin{tabular}{l|l|l|l|l|l|l} 
(C) Rev. Inter. Educ. Sup. & Campinas, SP & v.2 & n.3 & p.552-572 & set./dez. 2016 & ISSN 2446-9424 \\
\hline
\end{tabular}


$<$ http://download.inep.gov.br/educacao_superior/enade/manuais/manual_do_enade_2809201 6.pdf>. Acesso em: 28 set. 2016 b.

BOFF, Paulo Roberto. Diretrizes e prática farmacêutica. Pharmacia Brasileira, n. 84, p. 5055. jan./fev., 2012.

CANAN, Silvia Regina. ELOY, Vanessa Taís. Políticas de avaliação em larga escala: o ENADE interfere na gestão dos cursos? Práxis Educativa, Ponta Grossa, v. 11, n. 3, p. 621640set./dez. 2016. Disponível em:<http://www.revistas2.uepg.br/index.php/praxiseducativa> . Acesso em: 28 set. 2016.

CECCIM, Ricardo Burg; FEUERWERKER, Laura C. Macruz. Mudança na graduação das profissões de saúde sob o eixo da integralidade. Cadernos Saúde Pública, Rio de Janeiro, v.20, n.5 p.1400-1410, set./out. 2004.

CECY, Carlos. Diretrizes Curriculares - Dez Anos. Boletim da Abenfarbio: Revista Pharmacia Brasileira, n. 80, p. 53-60, fev./mar. 2011.

DIAS SOBRINHO, José. Avaliação e transformações da educação superior brasileira (19952009): do Provão ao SINAES. Avaliação, Campinas, v. 15, n. 1, p. 195-224, 2010.

FRANCISCO, Thiago Henrique Almino et al. Construções teóricas sobre o SINAES: Inferências sobre os principais desafios do Sistema Nacional de Avaliação da Educação Superior Brasileira. In: COLÓQUIO INTERNACIONAL SOBRE GESTÃO UNIVERSITÁRIA NAS AMÉRICAS, 12., 2012, Florianópolis. [Anais do...]. Florianópolis: UFSC; INPEAU, 2012. Disponível em: <http://repositorio.ufsc.br/xmlui/handle/ 123456789/97622>. Acesso em: 28 set. 2016.

FRANCISCO, Thiago Henrique Almino; MONTEIRO, Erika Cristina Mendonça de Sousa. Uma reflexão sobre o ENADE: as ações para a gestão de um importante elemento da avaliação. In: SIMPÓSIO AVALIAÇÃO DA EDUCAÇÃO SUPERIOR, 2., 2016, Porto Alegre. Anais do AVALIES... Porto Alegre: UFRGS, 2016.

FURTADO, Vivian da Silva. Análise do processo de implementação das Diretrizes Curriculares Nacionais do Curso de Graduação em Farmácia no Estado do Rio de Janeiro: um estudo exploratório. Dissertação (Mestrado em Saúde Coletiva) - Instituto de Medicina Social da Universidade do Estado do Rio de Janeiro, 2008.

HORTA, Cecília Eugenia Rocha (Org.). SINAES : avanços e desafi os na avaliação da educação superior. In: ABMES Cadernos 29. Brasília: ABMES Editora, 2014. 98 p.

JAPIASSU, Hilton. O sonho transdisciplinar e as razões da filosofia. RJ: Imago, 2006.

LEE, Lung-Sheng; WEI, Yen-Shun; WANG, Li-Yun. Higher education institutional and program evaluations in Taiwan and the emerging roles of higher education evaluation and accreditation Council of Taiwan (HEEACT). In: INTERNATIONAL NETWORK FOR QUALITY ASSURANCE AGENCIES IN HIGHER EDUCATION (INQAAHE), 2013, Taipei, Taiwan. Paper presented at the... Taipei, Taiwan: [s.d.], 2013. Disponível em: 
$<$ http://eric.ed.gov/?q=evaluation+system+of+higher+education\&id=ED541269 $>$. Acesso em: 28 set. 2016.

LU, Fletcher; LEMONDE, Manon. A comparison of online versus face-to-face teaching delivery in statistics instruction for undergraduate health science students. Advances in Health Sciences Education, v. 18, issue 5, p. 963-973, 2013. Disponível em:

<http://link.springer.com/article/10.1007/s10459-012-9435-3>. Acesso em: 28 set. 2016.

POLIDORI, Marlis Morosini et al. SINAES: Perspectivas e desafios na avaliação da educação superior brasileira. Ensaio: Avaliação Políticas Públicas de Educação, Rio de Janeiro, v. 14, n. 53, p. 425-436, out./dez. 2006.

POLIDORI, Marlis Morosini. Políticas de avaliação da educação superior brasileira: provão, SINAES, IDD, CPC, IGC e ... outros índices. Avaliação, Campinas, SP, v. 14, n. 2, p. $267-$ 290, jul. 2009.

\section{QUALTRICS. Questionários elaborados para a pesquisa de mestrado}

PPGMCS/PUCRS. Porto Alegre, 2013. Disponíveis em:

$<$ https://pucrs.qualtrics.com/SE/?SID=SV_6SiSs3p4ATrHrhj\&Preview=Survey\&BrandID=pucrs; https://pucrs.qualtrics.com/SE/?SID=SV_7Qbkd3TNiDc8nxr\&Preview=Survey\&BrandID=pucrs; https://pucrs.qualtrics.com/SE/?SID=SV_3r6dZXUNdg9O9tH\&Preview=Survey\&BrandID=pucrs; https://pucrs.qualtrics.com/SE/?SID=SV_6mQ0xL62ZaUBHFz\&Preview=Survey\&BrandID=pucrs>.

RISTOFF, Dilvo; GIOLO, Jaime. O Sinaes como Sistema. Revista Brasileira de PósGraduação, v. 3, n. 6, p. 193-213, dez. 2006.

RODRIGUES, Viviane Aparecida, PEIXOTO, Maria do Carmo Lacerda. Desvendando a caixa preta do ENADE: considerações sobre o processo de avaliação. Revista Trabalho \& Educação, Belo Horizonte, v.18, n.2, mai./ago. 2009.

ROTHEN, José Carlos; NASCIUTTI, Fernanda. A educação superior em prova: o perfil da educação superior apresentado pelos resultados do ENADE 2005 e 2006. In: REUNIÃO DA ANPED, 31., 2008, Caxambu. [Cadernos de...]. Caxambu: ANPED, 2008. [GT-11]. Disponível em: <http://www.anped.org.br/reunioes/31ra/trabalhos_gt.htm>. Acesso em: 28 set. 2016.

SANTANA, Silvina et al. Fighting for excellence: the case of the Federal University of Pelotas. High Education, v. 60, p.321-341, 2010. Disponível em: $<$ http://download.springer.com/static/pdf/783/art\%253A10.1007\%252Fs10734-009-93021.pdf?auth66=1385849664_472a681670ba0b2548d697d123dec152\&ext=.pdf $>$. Acesso em: 28 set. 2016.

SANTOMÉ, Jurgo Torres. Globalização e interdisciplinaridade o currículo integrado. Porto Alegre: Artmed, 1998.

SOUSA, José Vierira; FERNANDES, Ivanildo Ramos. Sinaes ou NeoSinaes? A avaliação da educação superior no Brasil à luz do Enade ampliado. In: SIMPÓSIO AVALIAÇÃO DA EDUCAÇÃO SUPERIOR, 2015, Porto Alegre. Anais do AVALIES... Porto Alegre: UFRGS, 2015. 
VARELA-PETITO, Gonzalo. Evaluating Public Higher Education in Mexico. Higher Education Management and Policy, v. 23, n. 2, Article 10, Sep 2011. Disponível em: $<$ http://eric.ed.gov/?q=evaluation+system+of+higher+education\&id=EJ946471 > . Acesso em: 28 set. 2016.

VERHINE, Robert Evan; DANTAS, Lys Maria Vinhaes. Avaliação da Educação Superior no Brasil: do Provão ao ENADE. Documento Preparado para o Banco Mundial. Dez. 2005. Disponível em: <http://www.isp.ufba.br/avalia\%C3\%A7\%C3\%A3o\%20da\%20Ed\% 20Superior\%20do\%20Provao\%20ao\%20ENADE.pdf>. Acesso em: 28 set. 2016.

ZOU, Yihuan et al. Quality of Higher Education: Organisational or Educational? A Content Analysis of Chinese University Self-Evaluation Reports. Quality in Higher Education, v.18, n.2, p.169-184, 2012. Disponível em: <http://eric.ed.gov/?q=evaluation+system +of+ higher+education\&id=EJ978514>. Acesso em: 28 set. 2016.

\section{Agradecimentos}

Este artigo faz parte do Projeto Pró-Ensino na Saúde, financiado pela Fundação Coordenação de Aperfeiçoamento de Pessoal de Nível Superior (CAPES), através do Edital nº 024/2010. 